\title{
Prevalence and correlates of use of digital technology for managing hypertension among older adults
}

\author{
Wei Xuan Lai $\mathbb{D}^{1 \times}$, Abhijit Visaria (iD) ${ }^{2}$, Truls $\varnothing$ stbye $^{1,3}$ and Rahul Malhotra $\mathbb{D}^{1,2}$ \\ (c) The Author(s), under exclusive licence to Springer Nature Limited 2022
}

\begin{abstract}
Hypertension is prevalent among older adults (60 years and above), but control of blood pressure (BP) remains suboptimal. While there is increasing interest in using digital technology for managing hypertension, information about the extent and potential correlates of such use among older adults remains scant. We assessed the prevalence and correlates of the use of digital technology for managing hypertension among older adults with hypertension. We also investigated if the use of digital technology was associated with BP or hypertension control. The use of digital technology (internet or digital apps) for information about or managing BP or hypertension was assessed among 1729 older adults diagnosed with hypertension participating in a national survey in Singapore. Regression analysis was used to assess the correlates (based on the Unified Theory of Use and Acceptance of Technology), and whether such use was associated with hypertension control or BP values. Digital technology for managing hypertension was used by $7.1 \%$ of older adults with hypertension. Those of higher age and with limitations in one or more activities or instrumental activities of daily living were less likely, while those with secondary education and above, and with stronger social network were more likely to use digital technology. There was no association between the use of digital technology and hypertension control. While users of digital technology had lower systolic (by $2.1 \mathrm{mmHg}$, adjusted $p$ value $=0.12$ ) and diastolic (by $1.6 \mathrm{mmHg}$, adjusted $p$ value $=0.13) \mathrm{BP}$ than non-users, the differences were not statistically significant. Given its low prevalence, there is potential for increased use of digital technology for managing hypertension among older adults with hypertension in Singapore. Initiatives to increase digital health use should target specific older adult subgroups.
\end{abstract}

Journal of Human Hypertension (2023) 37:80-87; https://doi.org/10.1038/s41371-022-00654-4

\section{INTRODUCTION}

Hypertension, a major risk factor for cardiovascular morbidity and mortality, is prevalent among older adults, aged $\geq 60$ years, worldwide [1-3]. Despite effective options for managing hypertension, control of blood pressure (BP) among older adults remains suboptimal [2, 4-6].

Self-care, which strives to co-opt and empower individuals in managing their own health, is a promising approach for better management of chronic diseases [7]. And, over the years, the use of digital technologies has become increasingly associated with self-care [8]. Digital technologies contributing to self-care range from the internet, which provides access to health information, to digital health technologies, such as apps and wearable devices [8].

Digital technologies present opportunities for improving the management of hypertension in an effective and cost-efficient manner $[9,10]$. They can play a role by improving anti-hypertensive medication adherence, increasing health awareness, engaging patients outside of healthcare institutions, and encouraging lifestyle modifications, which lead to improved health outcomes [11, 12]. Digital technologies for health also allow older adults to age independently by gaining autonomy and becoming more empowered in managing their health, and thereby improving their quality of life $[13,14]$. Despite the promise of, and interest in, digital technologies in hypertension management, information about the prevalence and correlates of the use of digital technology for managing hypertension among older adults is scant.

Singapore, a rapidly ageing Southeast Asian nation [15], is an excellent setting for investigating this issue. Nearly three-fourths (73.9\%) of older adults have hypertension and nearly two-thirds of older adults on treatment for hypertension have suboptimal BP control [16]. Singapore aims to become a "Smart Nation" - i.e. using smart technology and innovations to improve living conditions for all [17], an impetus that permeates to healthcare. For instance, Health Hub (https://www.healthhub.sg/), launched in 2015, serves as a one-stop web portal with an accompanying digital app for obtaining information about health conditions, accessing health records and managing medical appointments etc. [18].

Thus, using data from a recent, national survey of older adults in Singapore, we assessed the prevalence and correlates of the use of digital technology (internet or digital apps) for managing hypertension among older adults with hypertension. Identification of the potential correlates was based on the Unified Theory of Acceptance and Use of Technology (UTAUT), which has been applied to investigate user-centric factors affecting digital technology use [19]. We also investigated whether the use of digital technology was associated with hypertension control or BP values.

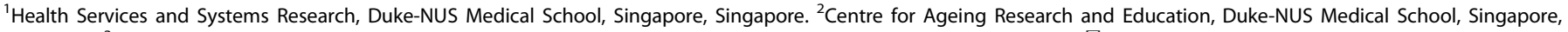
Singapore. ${ }^{3}$ Department of Family Medicine and Community Health, Duke University Medical Center, Durham, NC, USA. ${ }^{\mathrm{e}}$ email: laiweixuan@u.duke.nus.edu 


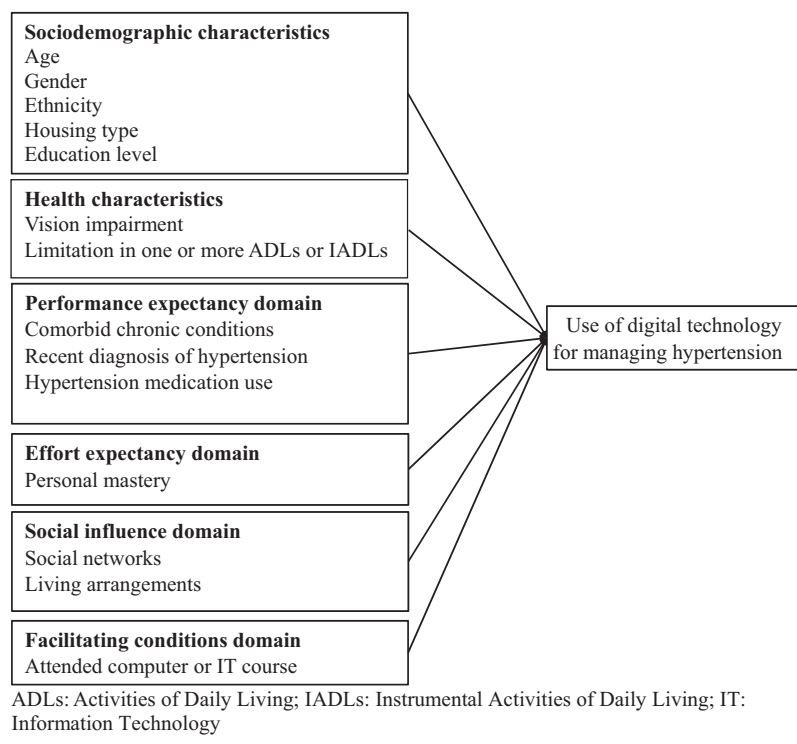

Fig. 1 Potential correlates of use of digital technology for managing hypertension adapted into a framework based on the Unified Theory of Use and Acceptance of Technology. The correlates are categorized into sociodemographic characteristics, health characteristics, performance expectancy domain, effort expectancy domain, social influence domain and facilitating conditions domain. Each category is associated with the use of digital technology for managing hypertension.

\section{METHODS}

\section{Data and analysis sample}

Data from "Transitions in Health, Employment, Social engagement and Inter-Generational transfers in Singapore Study" (THE SIGNS Study), a nationally representative, longitudinal study (2 waves: 2016-2017, and 2019) of community-dwelling Singapore citizens and permanent residents, aged $\geq 60$ years at wave 1 , was used. Informed consent was taken from all participants, which was approved by the Institutional Review Board at the National University of Singapore. Questions on the use of the internet or digital apps for health purposes were asked only in wave 2 (THE SIGNS Study-II) [16]. Of the 2887 participants in THE SIGNS Study-II, 1729 participants (59.8\%) who reported having been diagnosed by a health professional to have hypertension, and were therefore queried about their use of digital technology for managing hypertension, constituted the analysis sample.

\section{Use of digital technology for managing hypertension-Yes/No} THE SIGNS Study-II participants reporting a diagnosis of hypertension were asked if they had used the internet or an app on a phone or tablet in the past one month to "get more information about or to help manage their BP or hypertension". Those who responded yes were considered users of digital technology. For users, the frequency or duration of use within the past one month was not assessed in the survey.

\section{Potential correlates}

Potential correlates of the use of digital technology were categorized, based on the UTAUT [19] into four domains: performance expectancy, effort expectancy, social influence and facilitating conditions. Additionally, older adult sociodemographic and health characteristics were also considered, representing the larger personal context that may influence the use of digital technology [20-22]. The correlates considered are summarized in Fig. 1.

Sociodemographic characteristics included age (in years) at time of THE SIGNS Study-II (categorical [62-69/70-79/80 and above] for assessing prevalence of use of digital technology, and continuous for the logistic regression model); gender (male/female); ethnicity (Chinese/non-Chinese), education level (no formal education or primary education/secondary education and above); and housing type (1-3 room government-built flat/ $\geq 4$ room government-built flat or private housing). Education level and housing type represented socio-economic status [23]. Health characteristics included vision impairment (i.e. self-rated fair or poor vision or inability to see), and limitation in one or more activities of daily living (ADLs) or instrumental ADLs (IADLs), and both were coded as dichotomous (yes/no).

The performance expectancy domain of the UTAUT relates to the perceived improvement in health outcomes by using digital technology $[24,25]$. The presence of additional chronic diseases, as well as other hypertension-related variables may affect the potential perceived improvement in hypertension status that one may expect from using digital technology. Variables (all dichotomous-yes/no) considered in this domain were: comorbid chronic conditions other than hypertension; whether hypertension had been diagnosed recently (i.e. after wave 1 and prior to wave 2 of THE SIGNS Study); and current anti-hypertensive medication use.

The effort expectancy domain reflects the degree to which new technology is perceived to be understandable and easy to use [24, 26]. Individuals with a higher degree of personal mastery may be better able to cope with difficulties in using digital technology. We assessed personal mastery using the five-item Pearlin Mastery Scale [27]. Its summary score was categorized into tertiles for presenting prevalence of use of digital technology, and was used as a continuous variable for the logistic regression model.

The social influence domain relates to the degree to which the perception of "important others" can influence the behaviour of technology users $[19,28]$. We considered social influences both outside and inside the home. The participants' social network (relatives and friends) outside the household was determined using a modified version of the Lubben Social Network Scale-Revised [29]. Its summary score was categorized into tertiles for presenting prevalence of use of digital technology and was used as a continuous variable for the logistic regression model. Living alone (yes/no) represented opportunities to have social interactions within the household.

The facilitating conditions domain relates to factors in a user's environment that objectively facilitate use of digital technology by making technology use easier [30]. Singapore promotes lifelong learning by providing access to and subsidies for courses for middle-aged and older adults [31]. Thus, a participant's partaking in a computer or information technology (IT) education or training course in the past 12 months (yes/no) was considered as a facilitating condition.

Of the 1729 participants in the analysis sample, 172 (9.9\%) had missing values for the personal mastery or social network variables; for most of these $(n=154)$ it was because the scales assessing these variables were not administered to proxy respondents who were responding on behalf of older adults unable to respond themselves due to health reasons. Single mean imputation for the missing values was performed for these two covariates, whereby the mean value of the scale scores in the stratum that the participant belonged to, defined in terms of age group, gender, ethnicity and ADL/IADL limitation status, was imputed for the missing value.

\section{Hypertension control-Yes/No}

Three BP measurements were taken using a digital monitor (Omron HEM762), at 1-min intervals, for willing participants ( $n=1682$ [97.3\%] of the 1729 participants) by trained interviewers (trained using didactic instruction, demonstration, and role-play). The measurements were taken following completion of the study questionnaire. The interviewers were instructed to measure BP in the left arm (conducted for $95.1 \%$ of participants), or if the respondent reported any injury or health condition that precluded measurement in the left arm, in the right arm (4.9\%). Participants were seated, with their arm supported on a flat surface so that the cuff was at the same level as the heart (reported by interviewers as the position for $98.5 \%$ of participants). The 2 nd and 3 rd readings were averaged to obtain systolic (SBP) and diastolic (DBP) BP values. Hypertension control was defined as SBP $<140 \mathrm{mmHg}$ and $\mathrm{DBP}<90$ $\mathrm{mmHg}$, according to the American Heart association guidelines [32].

\section{Statistical analysis}

The distribution of the potential correlates were summarized using mean \pm standard deviation (for continuous variables) or proportion (for categorical variables). Prevalence of use of digital technology for managing hypertension, overall and by categories of the potential correlates were assessed. The association between the potential correlates and use of digital technology was determined using multivariable logistic regression. 
Furthermore, a sensitivity analysis was conducted, limiting the analysis to the 1557 participants without missing values on the personal mastery or social network scales - the findings are presented in Supplementary Table 1. The association of use of digital technology with hypertension control or BP values was assessed among the 1682 participants for whom $\mathrm{BP}$ was measured using logistic (for hypertension control) or linear (for SBP and DBP) regression, both without and with adjustment for age, gender, ethnicity, education level, housing type, vision impairment, limitation in one or more ADLs or IADLs, and whether BP measurements were done in the left arm and while sitting. All analyses, conducted using SAS University Edition, were weighted using attrition-adjusted survey sampling weights.

\section{RESULTS}

Table 1 presents the distribution of the potential correlates, prevalence of the use of digital technology across their categories, and their adjusted association with the use of digital technology for managing hypertension. The weighted prevalence of the use of digital technology for managing hypertension among older adults with hypertension in Singapore was $7.1 \%$. Sociodemographic and health characteristics as well as one of the UTAUT domains (social influence) were associated with the use of digital technology in multivariable analysis. The odds of use of digital technology declined with higher age (adjusted odds ratio [95\% confidence interval]: $0.93[0.90,0.96])$ and was higher for those with secondary and above education (4.98 [3.33,7.43]) versus no formal education or primary education. Those with, versus without, limitation in one or more ADLs or IADLs $(0.20$ $[0.07,0.57])$ were less likely to use digital technology. Social influence mattered - a stronger social network outside the household $(1.03$ [1.02,1.05]) was associated with higher odds of use of digital technology. The sensitivity analysis results were similar (Supplementary Table 1).

While the proportion with hypertension control was higher among those who had used digital technology for managing hypertension (63.8\%) versus those who had not (36.3\%), the corresponding unadjusted (1.39 [1.00, 1.85]) and adjusted (1.16 $[0.84,1.60])$ odds ratios did not support an association between use of digital technology and hypertension control. Based on results from adjusted linear regression models, users of digital technology had lower SBP (by $2.1 \mathrm{mmHg}, p$ value $=0.12$ ) and DBP (by $1.6 \mathrm{mmHg}, p$ value $=0.13$ ) versus non-users, although the difference was not statistically significant.

\section{DISCUSSION}

We estimated the prevalence and correlates of the use of digital technology for managing hypertension among older adults with hypertension in Singapore, and assessed the difference in SBP and DBP between users and non-users. In doing so, our study contributes to the literature in three ways. It is the first study to identify to what extent older adults with hypertension use digital technology specifically for their condition as well as the potential drivers and barriers to such use. Previous studies have either focused on digital technology use for health purposes in general or are not specific to older adults with hypertension [33, 34]. Second, it observed a low prevalence, $7.1 \%$, for the use of digital technology, thereby highlighting an opportunity to increase the use of digital technology for managing hypertension among older adults. Third, it found SBP and DBP to be lower, although not statistically significant, among users of digital technology for managing hypertension versus non-users.

Less than 1 in 10 older adults (7.1\%) with hypertension in Singapore had used the internet or an app to manage their hypertension in the past month. Studies from other developed countries have reported that $16.5-36.5 \%$ of older adults with hypertension use health apps [33, 34]. However, any comparison must be done with caution as estimates in these studies are based on the use of health apps not specific to managing hypertension or $\mathrm{BP}$, and have a different reference time for assessing use. Nonetheless, the prevalence in Singapore is low. Less access to the internet or digital devices that enable the use of digital technology among older adults in general, and especially in comparison to those younger, is likely a contributing reason. In Singapore, older adults have the lowest internet use (58\%) compared to other age groups (89\%) [35]. In our analysis sample, only $66.5 \%$ reported using a smartphone, laptop or computer regularly. However, the much lower prevalence, at $7.1 \%$, of the use of digital technology for managing hypertension, suggests that internet access or use for any purpose does not directly translate into its use for health purposes. Nevertheless, the low prevalence does point to the immense scope for increasing use of digital technology for managing hypertension among older adults.

A relevant theory for understanding how new innovations, such as the use of digital technology for managing health, spread within a society, is the Diffusions of Innovations Theory [36, 37]. The theory posits the first $16 \%$ of a population that adopt new innovations as "innovators" and "early adopters", represent opinion leaders and influence other segments of the population in facilitating the diffusion of an innovation. Given that only $7.1 \%$ older adults had used digital technology for managing hypertension in our study, it seems that the innovation of using digital technology for managing hypertension is still limited to "innovators" and "early adopters" in Singapore. Furthermore, by identifying personal characteristics of "innovators" and "early adopters", we can understand which older adult subgroups are not yet users, and thus should be focused on more for further expanding use of digital technology for health purposes among older adults.

Our analysis showed that those older were less likely and those better educated were more likely to be users. The inverse association with age is consistent with other studies examining the use of digital technology in general by older adults [35, 38, 39]. Education has consistently been shown to be associated with the use of digital technology [39-41]. Future cohorts of older adults in Singapore will have a greater proportion of those with secondary or higher education [42], thus it is likely that digital technology will play a larger role in self-management of chronic health conditions like hypertension by older adults in the future.

ADL or IADL limitations were associated with lower odds of use of digital technology for managing hypertension in our study. This is in line with previous work that posits that age-related health changes, such as decline in psychomotor coordination, pose significant barriers to the use of digital technology [43,44]. Older adults with $A D L$ and IADL limitations typically have poorer physical and cognitive performance $[45,46]$. Hence, websites and apps should incorporate features designed for older adults with ADL limitations, for example, larger 'tap targets', clear navigation cues, and fewer scroll bars and pull-down menus [47]. Health information on these webpages and apps should also be easy to understand for older adults with poorer cognitive abilities [48]. Lastly, managing the underlying clinical causes of $A D L$ or IADL limitations will help in promoting the use of digital technology.

Our study showed that social influence mattered in the use of digital technology for managing hypertension. Individuals with stronger social network outside the household were more likely to be users. Previous studies have also shown that older adults with good social network are more motivated to pick up digital technology due to the support and attention from family members [49]. It is also possible that older adults with stronger social network outside the household were connecting with their relatives and friends online, via communication apps or social media, and were thus also more likely to use the internet or apps 
Table 1. Distribution of the potential correlates and their association with the use of digital technology for managing hypertension among older adults in Singapore $(n=1729)$.

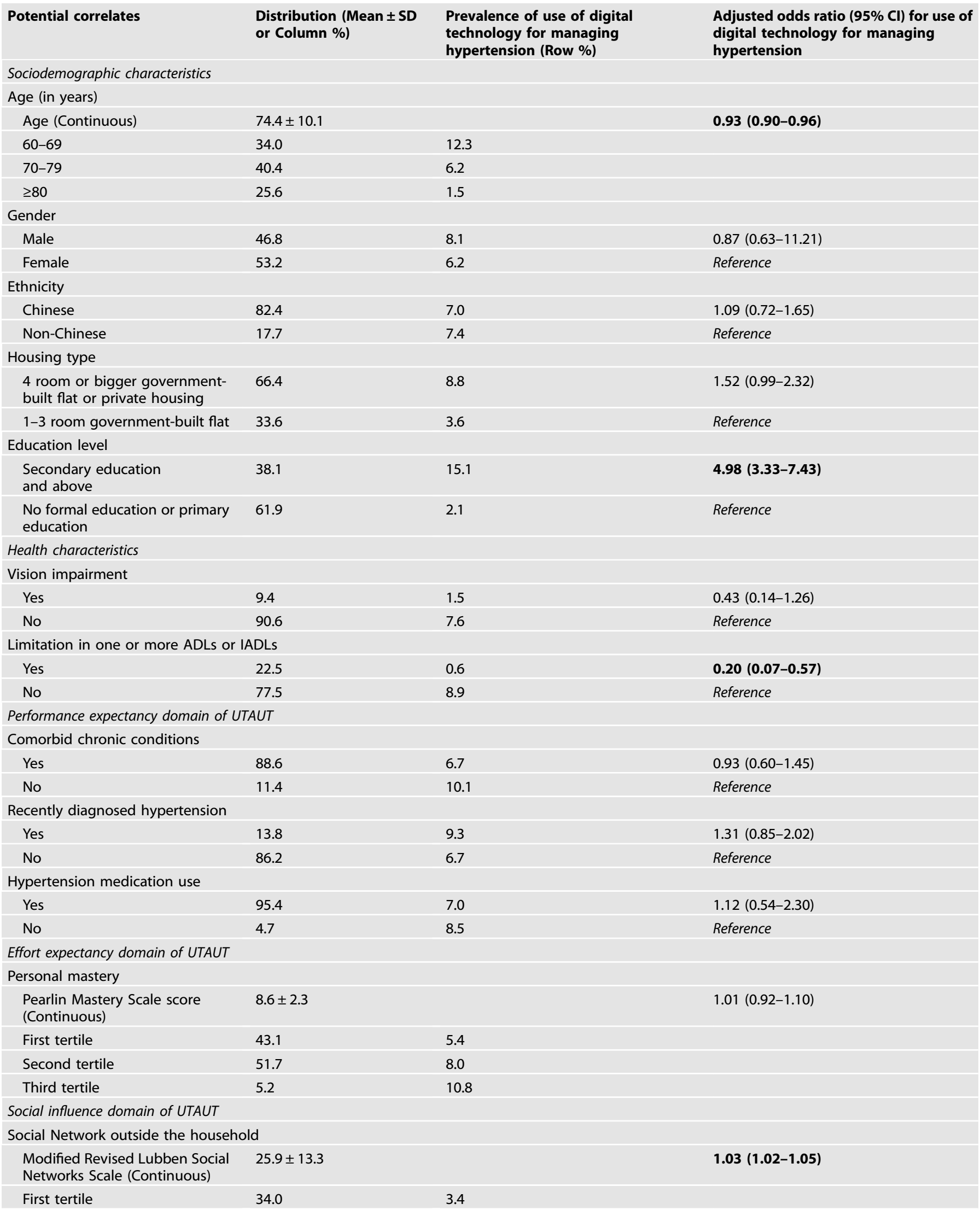




\begin{tabular}{|c|c|c|c|}
\hline Potential correlates & $\begin{array}{l}\text { Distribution (Mean } \pm \text { SD } \\
\text { or Column \%) }\end{array}$ & $\begin{array}{l}\text { Prevalence of use of digital } \\
\text { technology for managing } \\
\text { hypertension (Row \%) }\end{array}$ & $\begin{array}{l}\text { Adjusted odds ratio }(95 \% \mathrm{Cl}) \text { for use of } \\
\text { digital technology for managing } \\
\text { hypertension }\end{array}$ \\
\hline Third tertile & 31.2 & 11.4 & \\
\hline \multicolumn{4}{|l|}{ Living alone } \\
\hline \multicolumn{4}{|c|}{ Facilitating conditions domain of UTAUT } \\
\hline \multicolumn{4}{|c|}{ Computer or IT course in past 12 months } \\
\hline Yes & 3.8 & 7.4 & $0.50(0.23-1.11)$ \\
\hline No & 96.2 & 7.0 & Reference \\
\hline
\end{tabular}

$A D L$ s activities of daily living, $\mathrm{Cl}$ confidence interval, IADLs instrumental activities of daily living, IT information technology, SD standard deviation; UTAUT Unified Theory of Acceptance and Use of Technology.

Adjusted odds ratios that have a statistically significant correlation are bolded.

for other purposes, such as managing their health. Future interventions for improving digital access and literacy for the purpose of self-management of chronic health conditions should be mindful of the older adults who are socially isolated.

None of the potential correlates in the performance expectancy, effort expectancy domains and facilitating conditions UTAUT domains were associated with the use of digital technology. A recent diagnosis of hypertension, more severe hypertension requiring medication control, and the presence of other chronic health conditions did not seem to drive the perceived benefits from the use of digital technology for managing hypertension. The use of a generic personal mastery scale, rather than a specific scale assessing self-efficacy for use of the internet or digital devices, may have contributed to the lack of association of personal mastery with the use of digital technology. Similarly, while previous studies have expounded the benefits of public computer training for older adults in improving access to highquality internet health information [50,51], a possible explanation for the lack of association in our study is that the computer or IT courses taken by the study participants likely had variable content and scope, with not all focusing on accessing health information.

In our study, both SBP and DBP were lower, though not statistically significant, by $2.1 \mathrm{mmHg}$ and $1.6 \mathrm{mmHg}$ respectively, for older adults who used digital technology for managing hypertension versus those who did not. While the lower BP among users of digital technology did not translate into an association of the use of digital technology with hypertension control, it is still encouraging. For instance, this difference in SBP and DBP is comparable to that seen subsequent to lifestyle modifications aimed at reducing $B P$, such as exercise and a low salt diet $[52,53]$. Furthermore, it has been reported that a reduction of $2 \mathrm{mmHg}$ in SBP is linked with a $7-10 \%$ a reduction in the risk of stroke, coronary heart disease, and related death [54-56]. However, our finding needs to be confirmed in future studies, especially intervention studies. Future observational studies should also assess the longitudinal impact of the use of digital technology for managing hypertension on BP levels and hypertension control.

In Singapore, the proportion of older adult internet users has increased 1.75-fold between 2014 and 2019 [35, 57], and a "Senior Go Digital" movement was launched in May 2020 realizing the digital exclusion of older adults in the face of lockdown and physical distancing measures for controlling COVID-19 [58]. However, our study suggests that these efforts may not be sufficient if they are not targeted specifically for the purposes of managing health conditions-despite the high prevalence of device use in our sample, the prevalence of using digital technology for managing hypertension remained low. Concurrently, consideration of the language profile of older adults while designing health apps and webpages will likely contribute in increasing use of digital technology for health purposes. For instance, Singapore has four official languages (English, Chinese, Malay and Tamil), however, $54 \%$ of older adults are unable to read in English [59]. It is possible that the content of apps and webpages providing information on or enabling management of BP or hypertension did not match the linguistic capabilities of all older adults with hypertension, contributing to the low prevalence of the use of digital technology for managing hypertension.

Our study has its limitations. First, the low number of older adults who used digital technology for managing hypertension limited our ability to assess the association between hypertension and many potential correlates, particularly those considered under the UTAUT. For instance, while those with vision impairment (versus without) or those living alone (versus with someone) had relatively low prevalence of use of digital technology, the confidence intervals around their point estimates in the logistic regression analysis were wide, resulting in a lack of an association. Future studies, with a greater number of participants overall, especially including more users of digital technology will be helpful in further discerning barriers and facilitators of use. Second, while we identified important correlates of the use of digital technology for managing hypertension, more research, particularly qualitative research, will be useful in elucidating the pathways linking the identified correlates with digital technology use. Such studies should also investigate the use of technology in more depth and assess its impact on health more broadly. Third, we measured use of digital technology in a relatively recent time period, i.e. within the past month, in order to assess the prevalence of current use. It may be possible that some older adults with hypertension are infrequent users of digital technology for managing their condition, potentially using the technology only at the time of an aggravation in their condition or after or just prior to a consultation with a doctor. Future studies that assess the use of digital technology at more regular intervals may help shed further light on the patterns of and factors associated with use. Lastly, information about the use of digital technology was based on self-report, and the frequency or duration of use was not captured. Future studies should consider objective measures of digital technology use and gather information on the frequency or duration of use.

Our study also has its strengths. It is the first to assess the prevalence and potential correlates of use of digital technology specifically for managing hypertension among older adults with hypertension. Previous studies have examined the use of digital technology for health purposes in general while our study 
analyzed health app or internet use specifically for hypertension management [33, 34]. Furthermore, hypertension control was based on the measurement of BP at the time of the survey and not self-reported. The sample used in this analysis was also nationally representative of older adults in Singapore.

\section{CONCLUSION}

Given its low prevalence, there is considerable scope for increasing use of digital technology for managing hypertension among older adults with hypertension in Singapore. Initiatives to increase such use should especially target older adults with no formal education or primary education and less socially connected to improve their engagement with digital technologies. Previous suggestions for improving digital technology adoption in older adults include having teachers experienced in teaching older adults, designing lessons and digital products to better suit older adults, and leveraging on informal learning at the community level [44, 60]. This study provides insights about segments of the older adult population in Singapore who would benefit from such efforts to improve digital technology adoption for health purposes.

\section{SUMMARY}

\section{What is known about this topic}

- The use of digital technology for the management of chronic health problems have gained attention as a cost-effective solution to the growing problem of chronic health diseases, especially amongst older adults [21, 39]. In hypertensionspecific studies, the use of digital technology have been promising in helping improve cardiovascular health, diagnose hypertension and manage hypertensive patients $[9,10]$.

- In Singapore, $73.9 \%$ of participants in a large nation-wide survey were found to have hypertension, with a large proportion (64.5\%) having suboptimal control of their blood pressure despite being on treatment [5]. No other study in Singapore was conducted to assess digital technology use amongst older adults for hypertension, representing a gap in our knowledge on the prevalence of use of digital technology.

\section{What this study adds}

This study adds to current knowledge about digital technology use in older adults specifically with hypertension in Singapore in three ways:

- First, it is the first study to specifically assess the prevalence and correlates of the use of digital technology for managing hypertension among older adults diagnosed with hypertension. Previous studies have either focused on digital technology use for health purposes in general or are not specific to older adults with hypertension.

- Second, our study observed a low prevalence, 7.12\%, for the use of digital technology for managing hypertension among older adults with hypertension in Singapore. This observation is surprising given the high levels of digital literacy in Singapore [35]. However, this presents an opportunity to increase the use of digital technology for managing hypertension.

- Third, SBP and DBP were lower among users of digital technology for managing hypertension versus non-users. This observational finding is definitely promising in the context of the use of digital technology for managing hypertension, though it should be confirmed in future studies, especially intervention studies.

\section{CODE AVAILABILITY}

The SAS code used for data analysis can be requested from the corresponding author.

\section{REFERENCES}

1. Forouzanfar MH, Liu P, Roth GA, Ng M, Biryukov S, Marczak L, et al. Global burden of hypertension and systolic blood pressure of at least 110 to $115 \mathrm{~mm} \mathrm{Hg}, 1990$ 2015. JAMA. 2017;317:165-82.

2. Bowling $C B$, Lee $A$, Williamson JD. Blood pressure control among older adults with hypertension: narrative review and introduction of a framework for improving care. Am J Hypertens. 2021;34:258-66. https://doi.org/10.1093/ajh/ hpab002.

3. Seow LSE, Subramaniam M, Abdin E, Vaingankar JA, Chong SA. Hypertension and its associated risks among Singapore elderly residential population. J Clin Gerontol Geriatrics. 2015;6:125-32.

4. Ahn S, Zhao H, Smith ML, Ory MG, Phillips CD. BMI and lifestyle changes as correlates to changes in self-reported diagnosis of hypertension among older Chinese adults. J Am Soc Hypertens. 2011;5:21-30. https://doi.org/10.1016/j. jash.2010.12.001.

5. Malhotra R, Chan A, Malhotra C, Østbye T. Prevalence, awareness, treatment and control of hypertension in the elderly population of Singapore. Hypertens Res. 2010;33:1223-31.

6. Ostchega $Y$, Dillon CF, Hughes JP, Carroll M, Yoon S. Trends in hypertension prevalence, awareness, treatment, and control in older U.S. adults: data from the National Health and Nutrition Examination Survey 1988 to 2004. J Am Geriatrics Soc. 2007;55:1056-65. https://doi.org/10.1111/j.1532-5415.2007.01215.x.

7. Kennedy A, Rogers A, Bower P. Support for self care for patients with chronic disease. Bmj. 2007;335:968-70.

8. Lupton D. The digitally engaged patient: Self-monitoring and self-care in the digital health era. Soc Theory Health. 2013;11:256-70.

9. Parati G, Pellegrini D, Torlasco C. How digital health can be applied for preventing and managing hypertension. Curr Hypertens Rep. 2019;21:40. https://doi.org/ 10.1007/s11906-019-0940-0.

10. Burke LE, Ma J, Azar KM, Bennett GG, Peterson ED, Zheng Y, et al. Current science on consumer use of mobile health for cardiovascular disease prevention: a scientific statement from the American Heart Association. Circulation. 2015;132:1157-213.

11. Dzau VJ, Balatbat CA. Future of hypertension: the need for transformation. Hypertension. 2019;74:450-7.

12. Logan AG. Transforming hypertension management using mobile health technology for telemonitoring and self-care support. Can J Cardiol. 2013;29:579-85.

13. Cresci MK, Novak JM. Information technologies as health management tools: urban elders' interest and ability in using' the internet. Educ Gerontol. 2012;38:491-506. https://doi.org/10.1080/03601277.2011.567185.

14. Rogers WA, Mitzner TL. Envisioning the future for older adults: autonomy, health, well-being, and social connectedness with technology support. Futures. 2017;87:133-9. https://doi.org/10.1016/j.futures.2016.07.002.

15. Malhotra R, Bautista MAC, Müller AM, Aw S, Koh GCH, Theng Y-L, et al. The aging of a young nation: population aging in Singapore. Gerontologist. 2019;59:401-10.

16. Chan A, Malhotra R, Visaria A, Sung P, Seng B, Tan Y. Transitions in Health, Employment, Social Engagement And Intergenerational Transfers In Singapore Study (THE SIGNS Study) - II: cross-sectional and longitudinal analyses of key aspects of successful ageing. 2020;139.

17. Woo JJ. Singapore's Smart Nation Initiative - A Policy and Organisational Perspective: 1-12. ScholarBank@NUS Repository. 2017. https://doi.org/10.25818/ vjdp-1gqf.

18. Ministry of Health, Singapore. One-stop health information and services portal provides access to key medical records and health content. 2015. https://www. healthhub.sg/Apps.

19. Venkatesh V, Morris MG, Davis GB, Davis FD. User acceptance of information technology: toward a unified view. MIS Q. 2003;27:425-78. https://doi.org/ 10.2307/30036540. JSTOR.

20. Cotten SR, Francis J, Kadylak T, Rikard RV, Huang T, Ball, C, et al. A tale of two divides: technology experiences among racially and socioeconomically diverse older adults. In: Zhou J, Salvendy G, editors. Human aspects of IT for the aged population. Design for aging. Springer International Publishing; 2016. p. 167-77. https://doi.org/10.1007/978-3-319-39943-0_16.

21. Francis J, Ball C, Kadylak T, Cotten SR. Aging in the digital age: conceptualizing technology adoption and digital inequalities. In: Neves BB, Vetere F, editors, Ageing and digital technology: designing and evaluating emerging technologies for older adults. Springer; 2019. p. 35-49. https://doi.org/10.1007/978-81-133693-5_3. 
22. Smith A. Older adults and technology use. Pew Research Center: Internet, Science \& Tech; 2014. https://www.pewresearch.org/internet/2014/04/03/usage-andadoption/.

23. Malhotra R, Malhotra C, Chan A, Østbye T. Life-course socioeconomic status and obesity among older Singaporean Chinese men and women. J Gerontol Ser B, Psychol Sci Soc Sci. 2013;68:117-27. https://doi.org/10.1093/geronb/gbs102.

24. Adams N, Stubbs D, Woods V. Psychological barriers to Internet usage among older adults in the UK. Med Inf Internet Med. 2005;30:3-17. https://doi.org/ 10.1080/14639230500066876.

25. Hill R, Beynon-Davies P, Williams MD. Older people and internet engagement: acknowledging social moderators of internet adoption, access and use. Inf Technol People. 2008;21:244-66. https://doi.org/10.1108/09593840810896019.

26. Magnusson L, Hanson E, Borg M. A literature review study of Information and Communication Technology as a support for frail older people living at home and their family carers. Technol Disabil. 2004;16:223-35. https://doi.org/10.3233/ TAD-2004-16404.

27. Pearlin $\mathrm{LI}$, Schooler C. The Structure of Coping. Journal of Health and Social Behavior. 1978;19:2-21. https://doi.org/10.2307/2136319.

28. Renaud K, van Biljon J. Predicting technology acceptance and adoption by the elderly: a qualitative study. Proceedings of the 2008 Annual Research Conference of the South African Institute of Computer Scientists and Information Technologists on IT Research in Developing Countries: Riding the Wave of Technology; 2008, p. 210-9. https://doi.org/10.1145/1456659.1456684.

29. Lubben J, Gironda M. Measuring social networks and assessing their benefits. Social networks and social exclusion: Sociological and policy perspectives, 20-34 (2004).

30. Steele R, Lo A, Secombe C, Wong YK. Elderly persons' perception and acceptance of using wireless sensor networks to assist healthcare. Int J Med Inform. 2009;78:788-801.

31. Lee $M$, Morris $P$. Lifelong learning, income inequality and social mobility in Singapore. Int J Lifelong Educ. 2016;35:286-312.

32. Carey RM, Whelton PK. Prevention, detection, evaluation, and management of high blood pressure in adults: Synopsis of the 2017 American College of Cardiology/American Heart Association Hypertension Guideline. Ann Intern Med. 2018;168:351-8.

33. Langford AT, Solid CA, Scott E, Lad M, Maayan E, Williams SK, et al. Mobile phone ownership, health apps, and tablet use in US adults with a self-reported history of hypertension: cross-sectional study. JMIR MHealth UHealth. 2019;7:e12228 https://doi.org/10.2196/12228.

34. Rasche $P$, Wille $M$, Bröhl C, Theis S, Schäfer K, Knobe M, et al. Prevalence of health app use among older adults in Germany: national survey. JMIR MHealth UHealth. 2018;6:e8619 https://doi.org/10.2196/mhealth.8619.

35. IMDA. Annual survey on infocomm usage in households and by individuals for 2019; 2019. Retrieved from https://www.imda.gov.sg/-/media/Imda/Files/ Infocomm-Media-Landscape/Research-and-Statistics/Survey-Report/2019-HHPublic-Report_09032020.pdf.

36. Dearing JW, Cox JG. Diffusion Of innovations theory, principles, and practice. Health Aff. 2018;37:183-90. https://doi.org/10.1377/hlthaff.2017.1104.

37. Haider M, Kreps GL. Forty years of diffusion of innovations: utility and value in public health. J Health Commun. 2004;9:3-11. https://doi.org/10.1080/ 10810730490271430.

38. Fang ML, Canham SL, Battersby L, Sixsmith J, Wada M, Sixsmith A. Exploring privilege in the digital divide: implications for theory, policy, and practice. Gerontologist. 2019;59:e1-e15. https://doi.org/10.1093/geront/gny037.

39. Sun $X$, Yan W, Zhou H, Wang Z, Zhang $X$, Huang $S$, et al. Internet use and need for digital health technology among the elderly: a cross-sectional survey in China. BMC Public Health. 2020;20:1386 https://doi.org/10.1186/s12889-020-09448-0.

40. Graham R. Group differences in attitudes towards technology among Americans. N Media Soc. 2010;12:985-1003. https://doi.org/10.1177/1461444809341436.

41. Chang J, McAllister C, McCaslin R. Correlates of, and barriers to, internet use among older adults. J Gerontological Soc Work. 2015;58:66-85. https://doi.org/ 10.1080/01634372.2014.913754.

42. Singstat. Education Profile and Key Educational Indicators. Base. 2020. http:// www.singstat.gov.sg/publications/reference/ebook/population/education-andliteracy.

43. Hawthorn D. Possible implications of aging for interface designers. Interact Comput. 2000;12:507-28.

44. Medeiros F, de L, Xavier AJ, Schneider IJC, Ramos LR, Sigulem D, et al. Digital inclusion and functional capacity of older adults living in Florianópolis, Santa Catarina, Brazil (EpiFloripa 2009-2010). Rev Bras Epidemiol. 2012;15:106-22.

45. Miller ME, Rejeski WJ, Reboussin BA, Ten Have TR, Ettinger WH. Physical activity, functional limitations, and disability in older adults. J Am Geriatrics Soc. 2000;48:1264-72. https://doi.org/10.1111/j.1532-5415.2000.tb02600.x.

46. Rajan KB, Hebert LE, Scherr PA, Mendes de Leon CF, Evans DA. Disability in basic and instrumental activities of daily living is associated with faster rate of decline in cognitive function of older adults. J Gerontology Ser A. 2013;68:624-30. https://doi.org/10.1093/gerona/gls208.

47. Zaphiris $P$, Ghiawadwala M, Mughal S. Age-centered research-based web design guidelines. $\mathrm{CHI}$ '05 Extended Abstracts on Human Factors in Computing Systems. 2005:1897-1900. https://doi.org/10.1145/1056808.1057050.

48. Czaja S, Beach S, Charness N, Schulz R. Older adults and the adoption of healthcare technology: opportunities and challenges. In: Sixsmith A, Gutman G, editors. Technologies for active aging. Springer US; 2013. p. 27-46. https://doi. org/10.1007/978-1-4419-8348-0_3.

49. Choi NG, DiNitto DM. The digital divide among low-income homebound older adults: Internet use patterns, eHealth literacy, and attitudes toward computer/ Internet use. J Med Internet Res. 2013;15:e93.

50. Chu A, Huber J, Mastel-Smith B, Cesario S. "Partnering with seniors for better health": computer use and internet health information retrieval among older adults in a low socioeconomic community. J Med Libr Assoc. 2009:97:12.

51. Xie B, Bugg JM. Public library computer training for older adults to access highquality Internet health information. Libr Inf Sci Res. 2009;31:155-62.

52. Dumler F. Dietary sodium intake and arterial blood pressure. J Ren Nutr. 2009;19:57-60. https://doi.org/10.1053/j.jrn.2008.10.006.

53. Fagard RH, Cornelissen VA. Effect of exercise on blood pressure control in hypertensive patients. Eur J Cardiovasc Prev Rehab. 2007;14:12-17. https://doi. org/10.1097/HJR.0b013e3280128bbb.

54. Ettehad D, Emdin CA, Kiran A, Anderson SG, Callender T, Emberson J, et al. Blood pressure lowering for prevention of cardiovascular disease and death: a systematic review and meta-analysis. Lancet. 2016;387:957-67. https://doi.org/ 10.1016/S0140-6736(15)01225-8.

55. Jafar TH, Gandhi M, de Silva HA, Jehan I, Naheed A, Finkelstein EA, et al. A community-based intervention for managing hypertension in rural South Asia. $\mathrm{N}$ Engl J Med. 2020;382:717-26. https://doi.org/10.1056/NEJMoa1911965.

56. Staessen JA, Fagard R, Thijs L, Celis H, Arabidze GG, Birkenhäger WH, et al. Randomised double-blind comparison of placebo and active treatment for older patients with isolated systolic hypertension. The Systolic Hypertension in Europe (Syst-Eur) Trial Investigators. Lancet. 1997;350:757-64. https://doi.org/10.1016/ s0140-6736(97)05381-6.

57. IMDA. Annual Survey on Infocomm Usage in Households and by Individuals for 2014; 2014. https://www.imda.gov.sg/-/media/Imda/Files/Infocomm-MediaLandscape/Research-and-Statistics/Survey-Report/2019-HH-Public-Report_0903 2020.pdf.

58. IMDA. New SG digital office established to drive digitalisation movement-1,000 digital ambassadors to be recruited by June 2020. Press Release; 2020. https:// www.imda.gov.sg/news-and-events/Media-Room/Media-Releases/2020/New-SGDigital-Office-Established-to-Drive-Digitalisation-Movement.

59. Singstat. Demographic, characteristics, education, language and religion. Census of Population 2020. 2021. https://www.singstat.gov.sg/-/media/files/publications/ cop2020/sr1/cop2020sr1.pdf.

60. Akinola S. How can we ensure digital inclusion for older adults? World Economic Forum. 2021. https://www.weforum.org/agenda/2021/10/how-can-we-ensuredigital-inclusion-for-older-adults/.

\section{AUTHOR CONTRIBUTIONS}

We confirm that this work is original and has not been published elsewhere, nor is it currently under consideration for publication elsewhere. Each named author has substantially contributed to conducting the underlying research and drafting this manuscript.

\section{FUNDING}

Transitions in Health, Employment, Social Engagement and Inter-generational Transfers in Singapore Study (THE SIGNS Study) Study was funded by Singapore's Ministry of Health $(\mathrm{MOH})$ under agreement number MOH-NUS RL2015-053. We acknowledge funding for electronic blood pressure monitors used in THE SIGNS Study through a grant obtained by the Nihon University Population Research Institute from the "Academic Frontier" Project for Private Universities: matching fund subsidy from Japan's Ministry of Education, Culture, Sports, Science and Technology (MEXT), 2006-2010.

\section{COMPETING INTERESTS}

The authors declare no competing interests. 


\section{ADDITIONAL INFORMATION}

Supplementary information The online version contains supplementary material available at https://doi.org/10.1038/s41371-022-00654-4.

Correspondence and requests for materials should be addressed to Wei Xuan Lai.
Reprints and permission information is available at http://www.nature.com/ reprints

Publisher's note Springer Nature remains neutral with regard to jurisdictional claims in published maps and institutional affiliations. 